\title{
Innovation in Iran's small and medium size enterprises (SMEs): Prioritize influence factors affecting innovation of SMEs, using analytic network process (ANP) method
}

\author{
K. Talebi ${ }^{1}$, M. Ghavamipour ${ }^{2 \star}$ and A. Irandust ${ }^{2}$ \\ ${ }^{1}$ Faculty of Entrepreneurship, University of Tehran, Tehran, Iran. \\ ${ }^{2}$ Entrepreneurship Management, University of AllamehTabataba'i, Tehran, Iran.
}

Accepted 14 June, 2012

\begin{abstract}
The purpose of this article is to prioritize the different types of innovation and influencing factors affecting innovations of small to medium size enterprises (SMEs) in Iran, using multiple criteria framework. Analytical network process (ANP) has been used to develop the framework, because of the dependency among measures and the antecedents. Yet another reason to use ANP is that it provides relatively more reliable results compared to the other similar methods. To achieve this goal the judgments of experts have been collected through interviews and questionnaires, without interacting and not knowing each other's judgments. As SMEs are historically considered to be the engine of economic growth and innovation which could be the heart of this engine, the results would prepare the ground for entrepreneurs, managers and strategists to better understand the related factors and direct their efforts toward implementing them based upon their relative importance. Our result show that innovations rarely occur in an isolated context where in the first five influencing factors we can find at least one factor from each cluster. The most influence factors affecting innovation in Iran's SMEs are: Stage of industry, demand, industry-university linkage, attitude toward change, and size and age.
\end{abstract}

Key words: Innovation, small to medium size enterprises (SMEs), entrepreneurship, analytical network process (ANP).

\section{INTRODUCTION}

This study is about prioritizing different type of innovation and the influence factors affecting them in small-medium size enterprises (SMEs) in Iran. SMEs play a pivotal role in the national economies of countries all around the world. Innovation is part of the characteristic of such enterprises. Industry is moving away from large vertically integrated firms, and flexible value chains are replacing them (Karpak and Topcu, 2010).

The business environment is becoming increasingly dynamic, complex and unpredictable where technology, globalization, knowledge and changing competitive

\footnotetext{
*Corresponding author. E-mail: ghavamipour@gmail.com.
}

approaches impact on overall performance. Stopford (2001) suggests that this change is the reason why many firms are seeking new ways of conducting business to create wealth. Arguably, change need not be detrimental-it can also bring opportunities that firms should seek to exploit (O'Regan et al., 2006).

Research shows that new small firms are continually entering the market with new ideas, products and processes (De Jong and Marsili, 2006). A number of British small, medium-size manufacturing enterprises (SMMEs) have survived and thrived through the release of innovative new products (Laforet and Tann, 2006). Thus, the contention is that small firms that innovate successfully would increase their chances of survival and growth. However, successful innovation is a complex task 
for a SME that does not have the means and know-how to invest in $R$ and $D$ activities and other influencing factors affecting innovation or cannot always convert research and development into effective innovation. Furthermore, O'Regan et al. (2006) note the many difficulties SMEs have, are often organization-specific. Moreover, they do not exactly know where to concentrate to have an innovation. Whilst, researchers often examine innovation in the context of large firms and they overlook innovation within small firms. The innovation literature in SMEs remains fragmented and usually concentrates on single case studies or qualitative interviews with managers (Laforet, 2008).

In the literature to somehow certain degree, factors influencing innovation of SMEs were listed separately but there is no complete model on it and of course they are not prioritized. Yet prioritizing can guide policy makers, institutions, management, and business owners in SME policy formation to make them more innovative and help the economic growth.

The Schumpeterian mode (1942) of the individual entrepreneur, which considers separately the three stages of invention (that is, research leading to the generation of new ideas), innovation that consists of the development of these new ideas into marketable products and finally, the diffusion process across the market, has been superseded by new models highlighting the interactive character of the innovation process. In these models, different factors are collaborating together to turn a new idea into a potentially successful innovation. According to these models, innovations rarely occur in an isolated context. On the contrary, innovations result from the interaction with other factors and firms increasingly rely on knowledge sources that are external to the firm (Mention, 2011).

Analytical hierarchy process (AHP) is one of the widely used approaches to prioritize multiple factors (Saaty and Peniwati, 2008). However, a limitation of AHP is the assumption of independence among various factors. Influence factors affecting innovation considered in this study are not independent. For example Size + Age would influence on $R$ and $D$ expenditures and it would influence the financial institutes in the country and all that could have an effect on different type of innovation.

All of these are among the factors influencing firms' innovation. In addition, different types of innovation are interdependent as well (such as technological innovation may cause product innovation or even new service innovation). Because of this interdependency, the factors that are less important individually might turn out to be more important when evaluated collectively. That is why we selected analytical network process (ANP) as a methodology.

We identified 4 different types of innovation and 21 influence factors affecting it mostly from literature search modified and expanded by our experts. Antecedents were divided into four clusters: organizational factor, business environmental factors, institutional factors and leadership/individual factors. Moreover, four different types of innovations were identified: product innovation, service innovation, management innovation and technological innovation.

In this study, we will first briefly introduce innovation of SMEs from the literature review. Then we will give a description of some factors we think need clarification, some of the others are self-explanatory and there is no need to explain them, thereafter we present the methodology used in this study including ANP and its innovative use for this particular study. Both individual and aggregated results obtained by eliciting the influence of each factor on others with respect to a controlling factor will be given and finally we present the conclusion and future.

\section{INNOVATION OF SMALL-MEDIUM SIZE ENTERPRISES (SMES)}

Innovation is traditionally viewed as taking place mostly within a single firm. But the increasing availability and mobility of knowledge workers, the flourishing of the internet and venture capital markets, and the broadening scope of possible external suppliers in the present age have undermined the effectiveness of the traditional innovation system (Chesbrough, 2003).

There is considerable amount of literature about innovation, and various models have been suggested to describe its nature, such as product innovation, service innovation, process innovation, technology innovation and managerial innovation; radical innovation and incremental innovation; systemic innovation and component innovation; technology-push and market-pull; and more recently closed innovation and open innovation. Models can also be divided according to their innovation processes (linear models, chain linked models, etc.), or according to the fitness for developed or developing countries, etc (Lee et al., 2010).

However, there have been few studies regarding an innovation model specialized for SMEs. The majority of literature limits its focus to the study of entrepreneurial traits or structural characteristics, but there is little examination of the embeddedness of innovation in SMEs (Paniccia, 1998). According to Laursen and Salter (2004), it is not statistically evident that larger firms are better than SMEs in new-to-the-world type innovation, meaning that SMEs may well have capacity for innovation, especially radical innovation. It is agreed that, while SMEs' flexibility and specificity can be advantages in accelerating innovation, few of them have sufficient capacity to manage the whole innovation process by themselves, and this encourages them to collaborate with other firms (Edwards et al., 2005). They can lack the resources and capabilities in manufacturing, distribution, marketing, and extended $R$ and $D$ funding, which are 
essential for transforming inventions into products or processes. As a result, while many studies have shown that SMEs tend to have a higher $R$ and $D$ productivity than larger firms (although there is considerable variation by industries), there is still much debate on assessing the innovativeness of SMEs because of their material or resource factor disadvantages. Or, we might say they do not know the exact critical points that put their energy on them.

Apart from this argument, SMEs have an obvious role in innovation: UK figures, for instance, show that (including sole traders) SMEs account for 99\% of business, $55 \%$ of non-governmental employment and $51 \%$ of turnover (SBS, 2001). Naturally, encouraging innovation in SMEs is central to policy initiatives for stimulating economic development at the local, regional, and even national levels (Leea et al., 2010). The question then becomes how to facilitate innovation in SMEs, trying to discover which factors contributed to the success (or failure) of their innovation efforts. And this study is for the SMEs to know the critical factors influencing their innovations. They could even get the weight of each different factor.

\section{INFLUENCE FACTORS AFFECTING INNOVATION IN SMALL-MEDIUM SIZE ENTERPRISES (SMES)}

The growth innovation literature provides many alternative conceptualizations and models for the interpretation of observed data. An innovation can be a new product or service, a new production process technology, a new structure or administrative system, or a new plan or program pertaining to organizational members. Therefore, organizational innovation, or innovativeness, is typically measured by the rate of the adoption of innovations, although, a few studies have used other measures (Damanpour, 1991).

Innovation is often used synonymously with technological innovation. Nevertheless, modern innovation literature distinguishes at least two main categories of innovation, that is, product and process innovation. Product innovations are defined as changes in the output of an enterprise or organization, in which the innovation can be either goods or services. Process innovations can be either technological innovations or innovations in the organization of an enterprise or managerial innovation (Kubeczko et al., 2006). In this study, we choose 4 different type of innovation such as product innovation, service innovation, technological innovation (Yam et al., 2010 ), and managerial innovation (Maria and Freitas, 2008).

Storey (1987) reminds that for many business owners, growth of their business is not an objective, they are targeting at survival. Research shows that new small firms are continually entering the market with new ideas, products and processes (De Jong and Marsili, 2006). A number of British small, medium-size manufacturing enterprises (SMMEs) have survived and thrived through the release of innovative new products. Thus the contention is that small firms that innovate successfully would increase their chances of survival and growth (De Jong et al., 2004). However, successful innovation is a complex task for a SME that does not have the means and know-how to concentrate on the critical influence factors.

In survey of the literature, there were many factors influencing innovation in even SMEs or big companies. But through our research we could not find a comprehensive model that has gathered all the factors or even all the most important factors affecting innovation in the SMEs. Most of the studies focus on one or some few aspects of the influence factors and perfectly analyze them. In this study we divided the factors into 4 clusters orgazational factors, business environmental factors, institutional factors, and leadership factors- that would be explained.

It is possible to talk about an organizational view of innovation in so far as the analysis of the process of innovation, and of the conditions of the success of innovation are treated basically by taking into account the internal organization of firms: such as B1.Size + Age, B2.Knowledge management system, B3.R and D expenditures, B4.Financial resource, B5.Ownership structure, B6.Technological diversification (Table 1).

Environmental uncertainty has long been viewed as a central problem for organizations since it creates difficulties for effective decision making (Liao and $\mathrm{Hu}$, 2007). Environmental uncertainty is defined as the organization's perceived inability to predict accurately the actions of customers and situations that comprise the external environment, due to a lack of information or an inability to discriminate between relevant and irrelevant information (Gupta and Govindarajan, 1984). It is generally accepted that managers' perceptions of the environment are more important than the actual environment. In other words, environments are neither certain nor uncertain in themselves, but thinking makes them so (Freel, 2005). Managerial perceptions of environmental uncertainty are determined by 'the predictability of conditions in the organizations environment'. Here still, the more complex and changing the environment, the higher the level of environmental uncertainty (NaranjoGil, 2009).

The contextual or business environmental category was defined as characteristics of the business context out of which the organization emerged and/or within which it operated. Five influence factors in the cluster of the business environment are: C1.stage of industry, C2.network externalities (spillover), C3.market structure, C4.knowledge appropriability, C5.demand (Table 2).

The institutional factors is define as: The dynamic capability approach to strategy emphasizes the key role of strategic management in appropriately adapting, integrating, and reconfiguring internal and external organizational skills, resources, and functional competencies 
Table 1. Organizational factors cluster.

\begin{abstract}
Size is identified as the most important organizational characteristic predicting innovation adoption among organizations (Fagerberg et al., 2005). Damanpour (1987) analyzed innovations in 57 libraries and he found that larger organizations adopted more technology than smaller organizations. In this vein, Chenhall (2003) argued that large organizations depended on sophisticated information and control systems. These B1. Size + Age techniques provided the organization with a greater degree of functional and organizational structure coordination that aids in effective managerial decision making. Furthermore, larger organizations may have greater access to the resources needed to implement innovations. Lacking such resources, smaller organizations are forced to make difficult tradeoffs in their investment choices and often forgo implementation of expensive technologies (Damanpour and Gopalakrishnan, 2001).
\end{abstract}

Cui et al. (2005) mentioned that KM capabilities consist of three interrelated processes: knowledge acquisition, knowledge conversion, and knowledge application (Liao and Wu, 2010). Knowledge is not only an important resource for a firm, but also it serves as a basic source of competitive advantage. Therefore, KM capabilities refer to the knowledge management processes in an organization that develop and use knowledge within the firm and in interaction with other factors cause innovations. system

\section{B3. RandD expenditures}

There are intriguing differences in the way in which $R$ and $D$ spending is related to the probability of introducing product versus process innovation. $R$ and $D$ spending is strongly directly associated with the introduction of a new product, but it is not a necessary condition for the introduction of a new process. The latter is strongly associated with spending on new fixed capital, which may be consistent with an important role for embodied technological progress. However, the effect of investment spending on new machines on the probability of introducing a process innovation is enhanced by $R$ and $D$ spending. This implies that there may be an important role for $R$ and $D$ in favoring the absorption of new more advanced technologies. Once they have been introduced, however, $R$ and $D$ does not significantly affect their effective use.

Azzone et al. (1997a) And Azzone and Noci (1998b) show that SMEs are companies with limited financial resources. Therefore, they cannot develop long processes of competence accumulation, not even allocate funds to ecological initiatives or the secondary aspects of the company's main activity. This lack of resources is an element hindering the development of environmental improvements (Jesu's $A^{\prime}$ ngel del and Beatriz, 2003).

Ownership structure — the concentration in a firm's ownership and the identity of a firm's ownersinfluences a firm's corporate governance, its strategies, and its performance. The separation of ownership and control provides managers with incentives for diversification or other activities that reduce shareholder value, but large shareholders can pressure managers to reduce diversification and increase company economic performance. Similarly, the identity of the owners of a company has implications for a company's objectives and the way managers exercise their power (Andrew et al., 2008).

B5. Ownership structure

Technological diversification can be motivated by the firm necessity to improve the quality of its products or reduce cost in one market, and it is also most likely that the firm can profit more from different research projects than from different products. Technological diversification can affect firm innovativeness, on the one hand, due to a risk reduction in firm research activities. On the other hand, technologically diversified firms can received more spillovers from other research activities that take place in the company.

B6. Technological diversification

toward changing the environment (Langlois and Robertson, 1995). However, firms are embedded in a larger institutional environment, and the behavior of each is governed by regulative, normative, and cognitive aspects (Scott, 1995). Delmas (2002) suggest that specific attention should be given to the institutional context, which can facilitate or hinder firms' dynamic capabilities and innovative strategies. Five influence factors in the cluster of institutional factors are: D1.public subvention, D2.protection of IPR, D3.financial institutes, D4.social networks, and D5.industry-university linkage (Table 3).

The individual/leadership category was defined as characteristics of organizational leaders or the entrepreneurs 'characteristic in authority positions that were influential in the decision making and moving the firm into innovations, such as E1.attitude to work change, E2.job tenure, E3.education, and E4.external relationship (Table 4) (Kimberly and Evanisko, 1981).

\section{METHODOLOGY}

The ANP is a generalization of the analytic hierarchy process, popularly known as AHP. AHP is a theory of prioritization that derives relative scales of absolute numbers known as 'priorities' from judgments expressed numerically on an absolute fundamental 
Table 2. Business environmental factors cluster.

\begin{abstract}
Industrial organization theory suggests that innovativeness differs across the industry life cycle. Utterback

\section{C1. Stage of} industry

(1994) concludes that innovation is higher during early stages of the life cycle and declines as industries mature. In addition, he suggests that product innovation is generally higher in early stages while process innovation grows in importance in later stages. Studying both assembled and non-assembled products, Utterback (1994) identified three distinct stages, namely a Fluid Phase, Transition Phase, and Specific Phase (Hansen, 2006).
\end{abstract}

One of the core insights provided by the network externalities literature is that the value of products in this category increases as the installed base of users increases in size. In that context, we delineate the two distinct phenomena of direct and indirect network externalities. A direct network externality describes the increase in product value associated with having additional users in the network. An indirect network externality describes the situation where focal product value is mediated by the supply of complementary and necessary goods and services. And it would lead to innovation. A key assumption in network externalities is that exploitation of competitors' research findings is realized through the interaction of the firm's absorptive capacity with competitors' spillovers (Dewa and Read, 2007).

\section{C2. Network externalities (spillover)}

\section{C3. Market structure}

Researches examine market orientation in relation to company performance, new product development and competitive structures of companies. In terms of new product development, Atuahene-Gima (1996) finds that market orientation has a positive impact on new product performance at the early stage of the PLC and incremental product innovation. On the other hand, Salavou (2005) suggests that technology orientation has a significant direct effect on product innovativeness in SME instead. Appiah-Adu and Singh (1998) also find a link between customer orientation, new product success and company performance. However, they indicate that high levels of market dynamism and competitive intensity do not necessarily result in an increased emphasis on customer orientation in SMEs (Laforet, 2008).

Appropriability conditions refer to the degree to which firms capture the profits associated with their innovative activity and are often considered reflecting the degree to which valuable knowledge spills out into the public domain. The emphasis here is on valuable knowledge, because if a competitor's knowledge spills out but the competitor has already exploited a first-mover advantage in the marketplace, this knowledge is no longer valuable to the firm and does not constitute a spillover by our definition. The level of spillovers, in turn, depends on the strength of patents within an industry, the efficacy of secrecy, and/or first-mover advantages (Cohen and Levinthal, 1990).

Public procurement has received a lot of attention in recent discussions on favorable innovation policy options, both on the European level, such as in the Barcelona Strategy (Commission, 2003) and the AhoReport (Commission, 2006), and on the national level. In Germany, for example, public demand for innovative products will be extended as part of the federal government's High-tech-Strategy. Examples are intelligent energy concepts for city halls or schools and the equipment of public service cars with novel types of engine/propulsion technologies (Aschhoff and Sofka, 2009).

C5. Demand

elements in the $j$ th cluster. Some of its entries may be zero corresponding to those elements which have no path of direct interaction (or influence) to other elements.

The directions of the arc (or arrow) and loop signify dependence such that the arc and loop pointing into a cluster indicate that its elements influence the elements in the cluster from which the arc is emanating.

This structural model incorporates the following types of dependence in a multilevel hierarchy: (1) hierarchic functional dependence as described by the downward arc from the upper level to the lower level clusters, (2) feedback dependence as described by the upward arc from the lower level to the upper-level cluster, (3) inner-dependence or self-feedback as indicated by loop at each cluster, (4) interdependence among clusters in a level as indicated by the (horizontal) arc between clusters belonging to the same level and (5) feedback control loop as indicated by the arc pointing to the goal cluster. The feedback control loop can be viewed as a structural dependence indicating that all the elements defined in the decision structure are relevant and influenced by the goal element, making the systems strongly connected. 
Table 3. institutional Factorscluster.

\begin{tabular}{ll}
\hline & Consequently, regions are characterized by different preconditions to undertake innovation (To dtling, and \\
D1. Public & Kaufmann, 1999). Innovation systems are rooted within a given set of national and subnational \\
subvention & institutions, and the role of supporting institutions, private and public, formal and informal, is of crucial \\
importance (Lundvall and Nielsen, 1999). And public subvention could be the important factors for the
\end{tabular}

Consequently, regions are characterized by different preconditions to undertake innovation (To dtling, and institutions, and the role of supporting institutions, private and public, formal and informal, is of crucial SMEs innovation growth.

We focus on endogenous selection of appropriability regimes as a missing link in explaining the complex relationship between IPR protection and innovation. In an increasingly digital economy, firms have more and more incentive to create obstacles to copying, reduce openness, and limit the spillover of information

D2. Protection of IPR

\section{D3. Financial institutes}

\section{D4. Social networks}

\section{D5. Industry- University linkage} to buyers and outside competitors. The effects of such "masking" activities have been investigated in the literature on IPR and technology transfer (Taylor, 1993). Inverted-U relationships between IPR strength and innovation are well known in the literature on innovation models (Akiyama and Furukawa, 2009). And it is important to know that a technology is partially appropriable if it can be imitated, but stronger IPR protection makes it harder to imitate.

Azzone et al. (1997a, b) and Azzone and Noci (1998 a, b) show that SMEs are companies with limited financial resources. Therefore, they cannot develop long processes of competence accumulation, not even allocate funds to ecological initiatives or the secondary aspects of the company's main activity. This lack of resources is an element hindering the development of environmental improvements (Noci and Verganti, 1999). It could clearly show the importance of financial institutes for the innovation of the SMEs.

Social networks are studied in different economic context in Bala and Goyal (1998), Young (1999), Chwe (2000) or Jackson and Wolinsky (1996) and many others. "An important factor affecting the adoption rate of any innovation is its compatibility with the values, beliefs, and past experiences of the social system", Rogers (1988). Economic behaviors are carried on and constrained by social networks, which constitute institutionalized foundations to individual preferences and decisions. Indeed, social capital theory enhances the ability of social network to originate economic comparative advantages: Granovetter (1973) focuses on weak ties/strong ties distinction, as discriminating the informational content of relations. Furthermore, intermediary positions on a relational network, regardless of the very strength of ties, can generate a gain in information and in control Burt. Hence, the situation of agents on the network is emphasized as providing differentiated values for individual actions (Deroian, 2002).

On this point, the literature discusses the notion of the National System of Innovation. To express the importance of forging liaisons and links between the various networks related to innovation in increasing an economy's capacity to innovate. Other authors, such as Etzkowitz and Leydesdorff (2000) have proposed the triple helix model, conceptually different from the one just mentioned in that it affirms the existence of a spiral pattern of relations and links between the three institutional actors: Industry, University and Government, in which the university tends to have a critical part to play in the context of a knowledge-based economy (Marquesa et al.,2006).
The input to the super matrix of a hierarchical network would depend on the presence and type of dependence among factors. The entries to the block matrices $\left(S_{i j}\right)$ in the initial super matrix are the estimated priorities that provide the relative strength of dominance of an element over another element in the cluster with respect to a common element from which the arc emanates. There are several algorithms to measure such priorities as described in Srdjevic (2005). The AHP eigenvector method is one of the popular methods used to quantify the relative dominance of the elements from pairwise comparison matrices. Saaty (1980) proposed the following eigenvalue formulation to obtain the desired ratio-scale priority vector (or weights) $\mathrm{w}$ of $\mathrm{n}$ elements:

$A w=\lambda_{\max } W_{y} \quad e^{T_{W}}=1$

Overall (ratio-scale) priorities can be derived based on the synthesizing concept of the super matrix. In raising the super matrix into a large power, the transmission of influence along all possible paths defined in the decision structure is captured in the process
(Saaty, 2001). The convergence of the initial priorities to a steady state or equilibrium value in the so-called limit super matrix provides a set of meaningful synthesized priorities from the underlying decision structure. Since the PRMEHN model defines a strongly connected digraph, its super matrix representation is a primitive irreducible matrix. Thus, the limit super matrix $L$ exists when the initial super matrix is standardized by its principal eigenvalue as shown by the following equation:

$\lim _{\mathrm{p} \rightarrow \infty}\left(\mathrm{s} / \mathrm{A}_{\max }\right)^{\mathrm{p}}=\lim _{\mathrm{p} \rightarrow \infty}(\overline{\mathrm{s}})^{\mathrm{p}}=\mathrm{L}$

Every column of this limit matrix is a unique positive column eigenvector associated with the principal eigenvalue Imax [(Nikaido, 1968) mathematical proof]. This principal column eigenvector corresponds to the stable priorities from the limit super matrix and can be used to measure the overall relative dominance of one element over another in a hierarchical network structure (Angelo et al., 2007). 
Table 4. individual/Leadership factors cluster.

\title{
E1. Attitude to work change Self-explanatory
}

The research in strategic management has indicated that certain experiential attributes of top managers have an association with organizational actions. Executive tenure has attracted

E2. Job Tenure perhaps the most attention and its inverse relationship to organizational change is well documented. For example, Gabarro (1987) observed that new CEOs make most substantial changes within the first 2.5 years of their tenure and then the number of changes trails off (Musteen et al., 2006).

\author{
E3. Education \\ Self-explanatory
}

E4.External relationship Self-explanatory

\section{ANALYTIC NETWORK PROCESS (ANP) STEPS}

As we explained before, analytic network process, is a decision making tool used in complex problems. It involves all kinds of relationship, dependency and feedback in the model and draws a systematical figure of the decision making problem. ANP is the more general form of analytic hierarchy process, which generates feasible solutions to hierarchical kind of decision problems.

In this research, using pairwise comparisons, all kinds of subcomponents are being evaluated through ANP. There is a 1-9 scale which is also developed by Thomas Saaty and the pairwise comparisons are measured through this scale (Saaty, 2005). Our method is consists of five main steps:

1) Performing pairwise comparisons on the elements of the model.

2) Generating weighted super matrix by putting the relative importance weights (eigenvectors), calculated from pairwise comparison matrices, within the super matrix.

3) Performing pairwise comparisons on the clusters.

4) Generating the weighted super matrix by weighting the blocks of the weighted super matrix, by the corresponding priorities of the clusters so that it can be column stochastic.

5) Generating the super matrix by raising the weighted super matrix to the power $2 k+1$, where $k$ denotes an arbitrary large number, until the weights converge and stays constant (Saaty, 2005).

\section{APPLICATION OF ANP INTO SMES' INNOVATION}

In model construction stage all elements affecting the SMEs innovation -influence factors and different type of innovation-, were determined first by reviewing the literature then eliciting the judgment of our experts. From the beginning there were many factors which were obtained from available literature. We asked the experts to regroup them into three clusters and requested them to choose only the important factors. For each cluster only five factors were introduced. Ultimately we give all the answers to one of the experts to choose the final model that he asked us to add one more cluster that was individual factors and by the acceptance of the authors the model has been chosen.

In order to represent the link among elements explicitly, an influence matrix can be constructed. Each element of the system is represented at one row and on respective column of the influence matrix. If the row element affects the column element the corresponding entry of the matrix is checked, otherwise the entry is empty, that is, no relation. If at least two row elements of any cluster affect a column element, question for pairwise comparison of row elements with respect to that column element are asked. If there is only one row element affecting a column element (that is, column C5 is only affected by row B5), there is no need to - and no change to- ask a pairwise comparison question. In the unweighted super matrix, the corresponding entry (Row C5- column B5) would have a priority value of 1 .

The influence matrix is given in Figure 1. There is inner dependence in every cluster. For example in innovation cluster since Technological innovation may cause product innovation or even new service innovation there is an inner dependence among type of innovation. In ANP as we talked before model inner dependence is depicted with a loop in a cluster. There is outer dependence in every cluster too. For example Size + Age would influence on $R$ and $D$ expenditures and it would influence on the financial institutes in the country and all that could have an effect on different type of innovation. This illustrates outer dependence between organizational factors cluster and institutional factors cluster. In ANP model feedback is depicted with an arrow in both directions between the clusters (Figure 2 Model).

A questionnaire of about 21 pages and 215 questions in 20 parts was developed to assess degree of influence of two factors with respect to a controlling factor. All the experts were academicians whose main research areas are SMEs and innovation and teach these courses in their universities. They all are involved in Iran's business situation especially in small business situation.

The inconsistencies among the experts' answers in most parts were beyond 0.1 even though there were up to 6 factors in firms' internal environment and the vary long lasting questionary. Therefore, pair wise comparison part of the interview was completed in one session and there was no need to reiterate, eliciting judgments to identify reasons of inconsistency and possibly to reduce it (Karpak and Topcu, 2010). Saaty suggest that each clusters contain less that 9 factors because the human mind cannot analyze more than that. All the experts where familiar enough with the factors and we do not have much problem with this part. But filling the questionary was really time consuming, it took more than $3 \mathrm{~h}$ to fill each questionary.

\section{INDIVIDUAL AND AGGREGATED RESULTS}

After gathering the questionnaires from the experts and set down in the software (super decisions) the results has been emerged. We laid down the answer from each expert's judgment individually and did the prioritizing for each one separately and an aggregate judgment was derived from the geometric mean of individual judgments. Then we used Microsoft Excel to sort them from largest to smallest (Table 5 for a portion of the first five factors according to each expert individually and combined values). Consequently, we synthesized a set of 


\begin{tabular}{|c|c|c|c|c|c|c|c|c|c|c|c|c|c|c|c|c|c|c|c|c|c|c|c|c|}
\hline & \multicolumn{4}{|c|}{ A: Innovation } & \multicolumn{6}{|c|}{ B: Organizational Factor } & \multicolumn{5}{|c|}{$\begin{array}{l}\text { C: Business } \\
\text { environment }\end{array}$} & \multicolumn{5}{|c|}{ D: Institutional factors } & \multicolumn{4}{|c|}{ E:Leadership } \\
\hline & A1 & A2 & A3 & A4 & B1 & B2 & B3 & B4 & B5 & B6 & $\mathrm{Cl}$ & $\mathrm{C} 2$ & C3 & C4 & C5 & D1 & D2 & D3 & D4 & D5 & E1 & E2 & E3 & E4 \\
\hline A1 & & & & & + & + & + & + & & + & & & + & & + & & & + & & & + & & & \\
\hline A2 & & 1 & & & + & + & + & + & & + & & & + & & + & & & + & & & + & & & \\
\hline A3 & + & + & & & + & + & + & + & & + & + & + & + & & + & & & + & & & + & + & & \\
\hline A4 & + & + & + & & & + & & & & & & & & + & & & & & + & + & + & + & & + \\
\hline B1 & + & + & + & + & 1 & + & + & + & + & + & & & + & + & & & & + & + & + & + & + & & + \\
\hline B2 & + & + & + & + & + & 1 & + & & & + & & + & & + & & & & + & + & + & + & & & \\
\hline B3 & + & + & + & & + & + & 1 & + & & + & & + & & + & + & & & + & & + & + & & & \\
\hline B4 & + & + & + & & & & + & 4 & & + & & & & & & & & + & & + & & & & \\
\hline B5 & + & + & + & + & & & + & + & & & & & & & & & & + & & & + & + & & + \\
\hline B6 & + & + & + & + & + & + & + & + & & & & + & & + & & & & + & & & + & & & \\
\hline C1 & + & + & + & + & + & + & + & + & & + & & + & + & & + & + & & + & + & + & + & & & \\
\hline$C 2$ & + & + & + & & + & + & + & & & + & & 4 & + & + & & & & & & & + & & & \\
\hline C3 & + & + & + & & + & & + & + & & + & & & & + & + & & & + & & & + & & & \\
\hline C4 & + & + & + & & + & + & & & & & & + & & & & & & & & & & & & \\
\hline C5 & + & + & + & & + & & + & + & + & + & + & & & & & & & + & & & + & & & \\
\hline D1 & + & + & + & & + & & + & + & & + & & & & & & & & + & & & & & & \\
\hline D2 & + & + & + & & + & + & + & & & + & & & & + & & & & + & & & + & & & \\
\hline D3 & + & + & + & & + & & + & + & + & + & & & + & + & & + & & & & & & + & & + \\
\hline D4 & + & + & + & + & & & & & & & & & & & & + & & + & & & + & & & + \\
\hline D5 & + & + & + & + & & + & + & + & & + & & + & & + & & + & & & + & & + & & + & + \\
\hline E1 & + & + & + & + & & + & + & & & + & & & & & & & & & + & + & & + & & + \\
\hline E2 & & & & + & & & + & & & & & & & & & & & & + & & + & & & \\
\hline E3 & & & & + & & + & + & & & + & & & & & & & & & + & & + & & & + \\
\hline E4 & + & + & + & + & & + & + & + & & + & & + & & & & & & & + & & + & & & \\
\hline
\end{tabular}

Figure 1. Influence matrix.

judgments given by each expert as the representative judgment for the entire group. Though they did not interact with each other during the paired comparisons, it is interesting that all three experts identified the same antecedents as the most influential factors affecting innovation of the SMEs.

According to the limit matrix priorities, Stage of industry $(9 \%)$ turned out to be the most influential factor affecting SMEs' innovation, followed by demand $(8.5 \%)$, industryuniversity linkage (6.8\%), attitude to work change (6.3\%), and size and age (5.5\%). Because all clusters have at least one indicator in aforementioned factors, we can conclude that all of the clusters are to somehow equally important and for getting innovative firms we shall concentrate in organizational factors, business environmental factors, institutional factors, and leadership factors. We can see the most important factors of each cluster on Table 5.

\section{CONCLUSION AND FUTURE STUDIES}

$R$ and $D$ expenditure, financial recourses or even financial institutes are often cited as the most influential factor affecting innovation of SMEs. However, our study shows that stage of industries is the most influential factor in SMEs' innovations following by demand, industryuniversity linkage, attitude to work change and size and age. As we assumed before, the inter-dependencies among the factors when be evaluated concurrently might show the factors that are less important individually might turn out to be more important.

What you think about stage of industry? Which stages you are in (for your selected industry)? Why it came out as the most important factor through all these factors? How innovation could be affected by stage of industry in Iran? And questions of the sort could be the subject for future studies.

Based upon innovation literature we can say that at the first stage of industry the competition is not direct, and the firms got advantages from the competitors because the industry is still developing. It is with the growth of the industry that direct and traditional competition gets triggered. Powerful companies started to make different kinds of barriers through new companies. These barriers are, controlling access to the sources, controlling distribution channel, and controlling knowledge and technology of the industry. This study with respect to our 


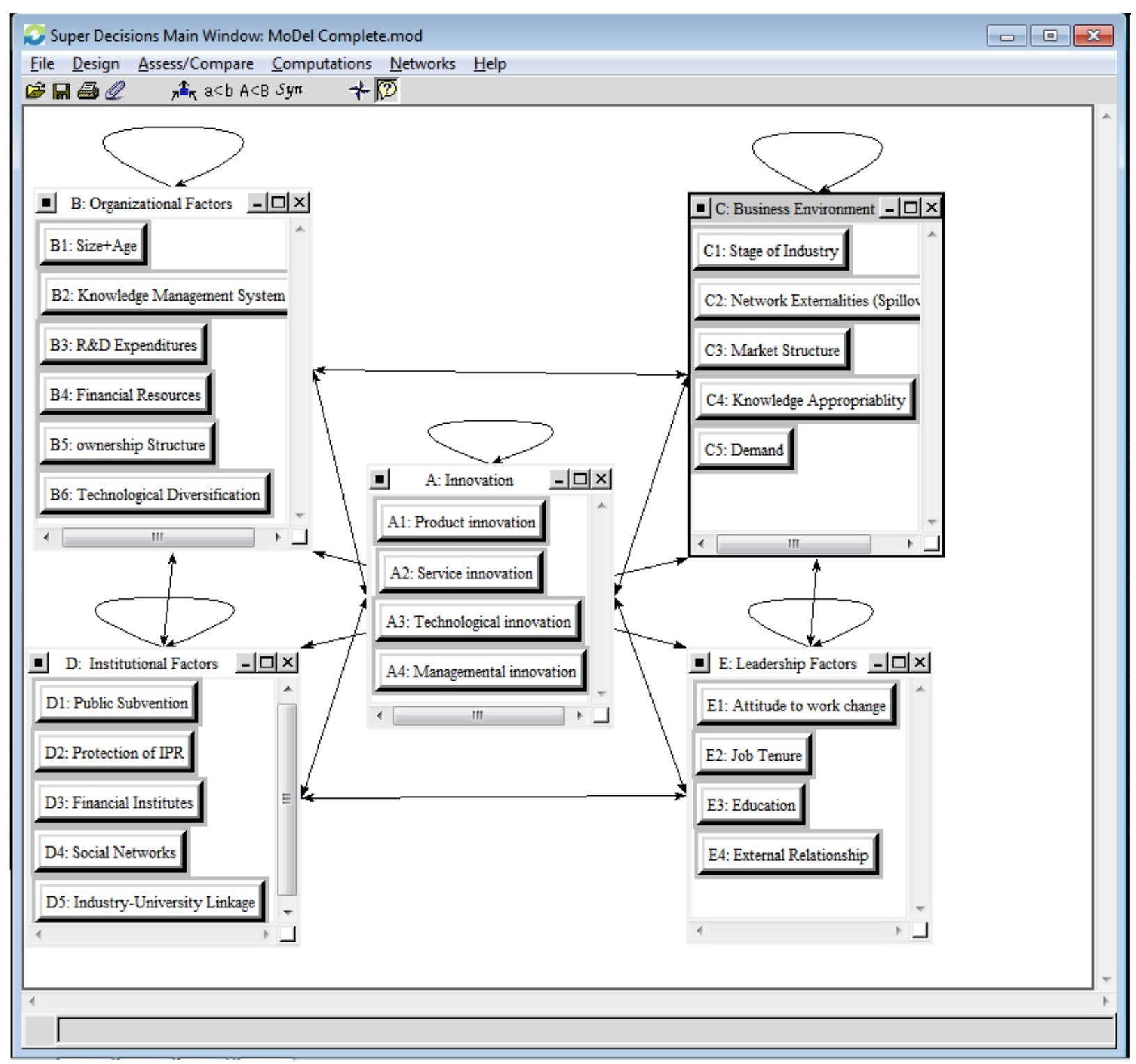

Figure 2. (ANP model in super decisions).

Table 5. Aggregated and individual results.

\begin{tabular}{llcccc}
\hline & First five factors & Expert 1 & Expert 2 & Expert 3 & Aggregated \\
\hline 1. & C1: Stage of Industry & 0.083432 & 0.091045 & 0.095771 & 0.089938 \\
2. & C5: Demand & 0.083921 & 0.078698 & 0.092449 & 0.084836 \\
3. & D5: Industry-university linkage & 0.063875 & 0.075935 & 0.065776 & 0.06833 \\
4. & E1: Attitude to work change & 0.061576 & 0.04987 & 0.079869 & 0.062595 \\
5. & B1: Size+Age & 0.05202 & 0.063207 & 0.049478 & 0.05459 \\
\hline
\end{tabular}

experts' opinion supports the effectiveness of such barriers toward the innovation of the SMEs in Iran. Also, many innovation experts believe that innovation in SMEs have a strong relationship with the stage of industry. This relationship can be tested through future studies.
It is very important to consider the point that innovations rarely occur in an isolated context. This has been exactly shown in our result where in the first five factors we can see at least one factor from each cluster.

Furthermore, this study could add something more to 
the innovation of the Iranian firms, business environment -stage of industry and demand - from the view of our expert is the most important cluster.

Through our knowledge, this is the first study prioritizing success factors influencing innovations of smallmedium size enterprises in Iran. Our fundamental argument in this paper was about the importance of factors that influence SMEs' innovation. Then the concentrations on this study could be very important for entrepreneurs, managers and strategist to better understand these factors and direct their efforts toward implementing them. Because our method was reliable and clear enough it could help the growth of the SMEs' innovation and slowly and constantly helps our country to go forward. Prioritizing these elements could be considered as guidance for us to set our programs and preferences through definite assumptions.

Furthermore, this research could be used in future studies, and it could be helpful for researchers to use ANP in their studies. ANP is a powerful methodology but you need to identify experts from whom the judgments are to be extracted. ANP is not very complex as a methodology; eliciting judgments from experts, however, could be quite time consuming. We have been very careful in designing the framework for obtaining expert judgment. We only asked the relative strength of direct influence of two factors with respect to the third (controlling) factor; second, third, fourth... degrees of influences are captured by ANP. ANP evaluates both quantitative and qualitative criteria.

\section{REFERENCES}

Akiyama T, Furukawa $Y$ (2009). Intellectual property rights and appropriability of innovation. Econ. Lett. 103:138-141.

Aschhoff B, Sofka W (2009). Innovation on demand-Can public procurement drive market success of innovations? Res. Policy 38:1235-1247.

Azzone G, Bertele U, Noci G (1997a). At last we are creating environmental strategies which work. Long Range Plan. 30:562-571.

Azzone G, Noci G (1998a). Seeing ecology and 'green' innovations as a source of chance. J. Organiz. Chang. Manage., 11(2): 94-111.

Azzone G, Noci G (1998b). Identifying effective PMSs for the deployment of 'green' manufacturing strategies. Int. J. Oper. Prod. Manag. 18(4):308-335.

Chesbrough H (2003). Open Innovation. Boston: Harvard Business School Press.

Chwe M (2000). Communication and coordination in social networks . Rev. Econ. Stud. 67:1-16.

Cohen WM, Levinthal DA (1990). Absorptive Capacity: A New Perspective on Learning and Innovation. Admin. Sci. Quart. 35:128152.

Commission E (2003). Investing in Research: An Action Plan for Europe. Brussels: Communication COM 266 final/2.

Commission E (2006). Creating an Innovative Europe-Report of the Independent Expert Group on RandD and innovation appointed following the Hampton Court Summit and chaired by Mr. Esko Aho. Luxembourg: EUR 22005.

Cui AS, Griffith DA, Cavusgil ST (2005). The influence of competitive intensity and market dynamism on knowledge management capabilities of MNC subsidiaries. J. Int. Marketing 13(3):32-53.

Damanpour F (1987). The Adoption of Technological, Administrative, and Ancillary Innovations. Impact of Organizational Factors, J.
Manag. 13:675-688.

Damanpour F (1991). Organizational innovation: A meta analysis of effects of determinants and moderators. Acad. Manag. J. 34(3): 555590.

Damanpour F, Gopalakrishnan S (2001). Dynamics of the adoption of product and process innovations in organizations. J. Manag. Stud. 28:45-65.

De Jong JPJ, Vermeulen PAM, O'Shaughnessy KC (2004). Effecten van innovatie in kleine bedrijven. $\mathrm{M}$ and $\mathrm{O}$ 58(1):21-38.

De Jong PJJ, Marsili O (2006). The fruit flies of innovations: a taxonomy of innovative small firms. Res. Policy pp. 213-229.

Jesu's $A^{\prime}$ ngel del, Beatriz JB (2003). A review of the literature on environmental innovation management in SMEs: implications for public policies. Technovat. 23:939-948.

Delios A, Zhou N, Xu WW (2008). Ownership structure and the diversification and performance of publicly-listed companies in China. Bus. Horiz. 51:473-483.

Delmas MA (2002). Innovating against European rigidities Institutional environment and dynamic capabilities. Manag. Res. 13:19-43.

Deroian F (2002). Formation of social networks and diffusion of innovations. Res. Policy 31:835-846.

Dewa N, Read S (2007). The more we get together: Coordinating network externality product introduction in the RFID industry. Technovat 27:569-581.

Fagerberg J, Mowery DC, Nelson RR (2005). In: The Oxford Handbook of Innovation. Oxford, UK: Oxford University Press.

Freel M (2005). Perceived environmental uncertainty and innovation in small firms. Small Bus. Econ. 25:49-64.

Gupta AK, Govindarajan V (1984). Business unit strategy, managerial characteristics, and business unit effectiveness at strategy implementation. Acad. Manag. J. 27:25-51.

Hansen E (2006). Structural panel industry evolution: Implications for innovation and new product development. Forest Policy Econ. 8:774783.

Karpak B, Topcu L (2010). Small medium manufacturing enterprises in Turkey: An analytic network process framework for prioritizing factors affecting success. Int. J. Prod. Econ. 125:60-70

Kimberly JR, Evanisko MJ (1981). Administrative innovation: The influence of individual, organizational, contextual factors on hospital adoption of technological and administrative innovations. Acad. Manag. J. 24(4):689-713.

Kubeczko K, Rametsteiner E, Weiss G (2006). The role of sectoral and regional innovation systems in supporting innovations in forestry. Forest Policy Econ. 8:704-715.

Laforet S (2008). Size, strategic, and market orientation affects on innovation. J. Bus. Res. 61:753-764.

Laforet S, Tann J (2006). Innovative characteristics of small manufacturing firms. J. Small Bus. Enterp. Dev. pp. 363-380.

Langlois RN, Robertson PL (1995). Firms, markets and economic change: a dynamic theory of business institutions. London: Routledge.

Lee S, Parkb G, Yoonc B,Parkd J (2010). Open innovation in SMEsAn intermediated network model. Res.Policy. 39:290-300.

Leea S, Parkb G, Yoonc B, Parkd J (2010). Open innovation in SMEsAn intermediated network model. Res. Policy 39:290-300.

Liao S, Hu T (2007). Knowledge transfer and competitive advantage on environmental uncertainty: an empirical study of the Taiwan semiconductor industry. Technovat. 27:402-411.

Liao SH, Wu CC (2010). System perspective of knowledge management, organizational learning and organizational innovation. Expert Syst. Appl. 37:1096-1103.

Lundvall BA, Nielsen P (1999). Competition and transformation in the learning economy, illustrated by the danish case. Revue d'Economie Industrielle 88:67-89.

Maria I, Freitas B (2008). Sources of differences in the pattern of adoption of organizational and managerial innovations from early to late 1990s, in the UK. Res. Policy 37(1):131-148.

Marquesa JPC, Carac JMG, Diz H (2006). How can universityindustry-government interactions change the innovation scenario in Portugal? The case of the University of Coimbra. Technovat 26:534542.

Mention AL (2011). Co-operation and co-opetition as open innovation 
practices in the service sector: Which influence on innovation novelty? Technovat pp. 44-53.

Naranjo-Gil D (2009). The influence of environmental and organizational factors on innovation adoptions: Consequences for performance in public sector organizations. Technovat 29:810-818.

Noci G, Verganti R (1999). Managing 'green' product innovation in small firms. Rand Manag. 29(1):3-15.

O'Regan N, Ghobadian A, Sims M (2006). Fast tracking innovation in manufacturing SMEs. Technovat 26:251-261.

Paniccia I (1998). One, a hundred, thousands of industrial districts. Organizational variety in local networks of small and medium-sized enterprises. Organiz. Stud. 19(4):667-699.

Rogers E (1988). Diffusion of Innovations, 3rd Edition. New York: Free Press.

Saaty T (1980). The Analytic Hierarchy Process. New York, USA: McGraw-Hill.

Saaty T (1996). Decision Making with Dependence and Feedback: The Analytic Network Process, first ed. Pittsburgh, USA: RWS Publications.

Saaty T (2001). Decision Making with Dependence and Feedback: The Analytic Network Process, second ed. Pittsburgh,USA: RWS Publications.

Saaty T (2005). Theory and Applications of the Analytic Network Process. Pittsburgh: RWS,Publications.
Saaty T, Peniwati K (2008). Group Decision Making: Drawing out and Reconciling Differences. Pittsburgh: RWS Publications.

Salavou H (2005). Do customer and technology orientation influence product innovativeness in SMEs? Some new evidence from Greece. J. Market. Manag. 21:307-338.

SBS (2001). Small and medium-sized enterprise (SME) statistics for the UK. Small Business Service, press release, 21 June.

Scott WR (1995). Institutions and organizations. California: SAGE Publications.

Srdjevic B (2005). Combining different prioritization methods in the analytic hierarchy process synthesis. Comput. Oper. Res. 32:18971919.

Taylor M (1993). TRIPS, trade, and technology transfer. Can. J. Econ. 26:625-637.

To dtling F, Kaufmann A (1999). Innovation systems in regions of Europe-a comparative perspective. Eur. Plan. Stud. 7: 699-717.

Yam RCM, Lo W, Tang EPY, Lau AKW (2010). Analysis of sources of innovation, technological innovation capabilities, and performance: An empirical study of Hong Kong manufacturing industries. Res. Policy (In Press). 